\title{
Evaluating Biomass of Juniper Trees (Juniperus pinchotii) from Imagery-Derived Canopy Area Using the Support Vector Machine Classifier
}

\author{
Mustafa Mirik*, Sriroop Chaudhuri, Brady Surber, Srinivasulu Ale, Robert James Ansley \\ Texas A\&M AgriLife Research (TAMAR), Vernon, USA \\ Email: ${ }^{*}$ mustafamirik@gmail.com
}

Received February 2, 2013; revised March 2, 2013; accepted March 10, 2013

Copyright (C) 2013 Mustafa Mirik et al. This is an open access article distributed under the Creative Commons Attribution License, which permits unrestricted use, distribution, and reproduction in any medium, provided the original work is properly cited.

\begin{abstract}
Both temporal and spatial magnitude, structure, and distribution of rangeland aboveground biomass (AGB) are important inputs for many necessities, in particular for estimating terrestrial carbon amount, ecosystem productivity, climate change studies, and potential bioenergy uses. Much of the remote sensing research previously completed has focused on determining carbon stocks in forested ecosystems with little attention directed to estimate AGB amount in rangelands. Our objectives were to: 1) identify and delineate individual redberry juniper (Juniperus pinchotii) plants from surrounding live vegetation using the support vector machine method for classifying two-dimensional (2D) geospatial imagery with a 1-m spatial resolution at two sites; and 2) develop regression models relating imagery-derived and fieldmeasured single tree canopy area and diameter for dry AGB estimation. The regression results show that there were very close and significant relationships between field measured juniper plant AGB and canopy area derived from the image classification with $\mathrm{r}^{2}>0.90$. These results suggest that spectral reflectance recorded on $2 \mathrm{D}$ high resolution imagery is capable to assess and quantify AGB as a quick, repeatable, and unbiased method over large land areas.
\end{abstract}

Keywords: Remote Sensing; Geospatial Imagery; Biomass; Juniperus pinchoti; Rangeland; Bioenergy; Terrestrial Carbon Budget

\section{Introduction}

Aboveground vegetation biomass (biomass hereafter) distribution, structure, and amount in rangeland regions are important in estimating terrestrial carbon and energy fluxes between atmosphere and biosphere and thus are major considerations in ecosystem processes or climate change research [1-4]. Vegetation on rangelands, characterized by woodlands, shrublands, and grasslands, provides essential ecosystem services, including forage for domestic and native herbivores, but is highly variable in spatial distribution and temporal growth patterns [5-9]. A world-wide phenomenon on many rangelands has been the expansion of woody plants into grassland and savanna areas in the last 150 years $[3,4,8,10]$. Increases in woody-plant abundance comprise a significant but highly uncertain fraction of the carbon budget world-wide $[3,6]$. Projecting future states of rangeland ecosystems in response to woody invasions and changes in climate,

${ }^{*}$ Corresponding author. edaphic, and disturbance regimes are strongly dependent on current assessment of woody biomass and distribution and the contribution of woody plants to total terrestrial biomass amount [6].

Traditional field-based biomass estimations of woody biomass through allometric functions are accurate, but are costly, tedious, time consuming, and usually limited to small land areas. Remote sensing-based biomass prediction is the most promising method at regional and global scales [2,11-18]. Over the last decade, a large number of studies have estimated biomass using twodimensional (2D) geospatial images, synthetic aperture radar (SAR) and LIDAR [2,11,13,16,19]. Numerous studies have documented that remote sensing techniques are highly efficient to assess woody plant biomass at multiple spatial and temporal scale $[11,12,20]$. Although small footprint radar backscatter and LIDAR data may be more accurate than 2D geospatial imagery for characterizing woody plant attributes, these data are expensive to acquire at present, and are limited by its narrow swathcoverage on each overpass due to high spatial resolution 
[4,15,21-23]. Two-dimensional high resolution geospatial imageries, such as TM, IKONOS, QuickBird, GeoEye, World View, are much more cost-effective and are now available for almost anywhere in the world [24]. Though such data have been widely used to quantify forest biomass, they have been rarely utilized for rangeland woody biomass assessment [24,25]. Research on high-resolution 2D geospatial images from satellite has evaluated algorithms to determine crown diameter, crown area, and other attributes in a wide range of forested areas [24,25]. For this reason, remote sensing studies quantifying rangeland biomass contribution to the total carbon budget are strongly needed.

Redberry juniper (Juniperus pinchotii; juniper hereafter) occupies more than 4.7 million ha of rangeland in the western half of Texas alone and extents to the neighboring states in the Southern Great Plains of the US [10]. Juniper is a native troublesome species, aggressively encroaching into rangeland due to reduced intensity and frequency of fires and livestock overgrazing. High densities of this and a closely related species in central TX, Ashe juniper (Juniperus ashei), can significantly decrease species diversity and grass production by competing for natural resources and can greatly trigger soil erosion [26].

The United States Department of Agriculture-National Agricultural Imagery Program (USDA-NAIP) imagery archive has entered public domain, providing exciting opportunities to advance rangeland research. We propose that periodically acquired NAIP images are adequate for quantifying biomass of individual juniper plants because of 1-m spatial resolution. Recently, Allometric models between field-measured redberry juniper above-ground mass (AGM) and physiognomic characteristics such as canopy area, diameter, and height were developed [10]. In addition, the potential of high-resolution QuickBird images to estimate Juniperus spp. tree volume and biomass was examined in which this type of optical imagery can be used for rapid and reliable measurements of tree volume and biomass [27,28]. The objectives of the present study were to 1) identify and delineate juniper from surrounding live vegetation using the support vector machine (SVM) classifier; 2) investigate the relationships between imagery-derived and field-measured canopy area and diameter; and 3) develop regression models relating imagery-derived and field-measured single tree attributes for estimation of total, wood, and leaf-twig biomass. Since the remote sensing biomass of juniper trees has not been well documented, we initiated this study to fill an important gap in the application of remotely assessed canopy area using the SVM method for discriminating juniper plants from background vegetation and estimating biomass components.

\section{Materials and Methods}

\subsection{Study Area}

Data were collected from two sites near the town of Crowell about 132-km west of Wichita Falls and 241-km east of Lubbock in north central Texas (Figure 1). The sites were located about within $10 \mathrm{~km}$ of each other on similar soil types: Site 1 (Whatley Ranch), $34^{\circ} 4^{\prime} \mathrm{N}$, 99 $44^{\prime} \mathrm{W}$; elev. 436-m in Foard County; Site 2 (Copper Break State Park), $34^{\circ} 6^{\prime} \mathrm{N}, 99^{\circ} 45^{\prime} \mathrm{W}$; elev. 443-m in Hardeman County. Total 30 years mean annual rainfall at Crowell is $616 \mathrm{~mm}$ [29]. The sites were dominated by juniper and honey mesquite (Prosopis glandulosa Torr.). Herbaceous understory consists of numerous cool-season $\left(\mathrm{C}_{3}\right)$ and warm-season $\left(\mathrm{C}_{4}\right)$ grass species dominated by perennial $\mathrm{C}_{4}$ grasses, tobosagrass (Pleuraphis mutica) and buffalograss (Bouteloua dactyloides). Other grasses are $\mathrm{C}_{3}$ mid-grass Texas wintergrass (Nassella leucotricha), $\mathrm{C}_{3}$ annual grass Japanese brome (Bromus japonicus) and other $\mathrm{C}_{4}$ mid-grasses such as vine mesquite (Panicum obtusum), sideoats grama (Bouteloua curtipendula), and dropseeds (Sporobolus spp.) [30]. Soils are fine-silty, mixed, thermic Typic Calciustolls of the Quanah series

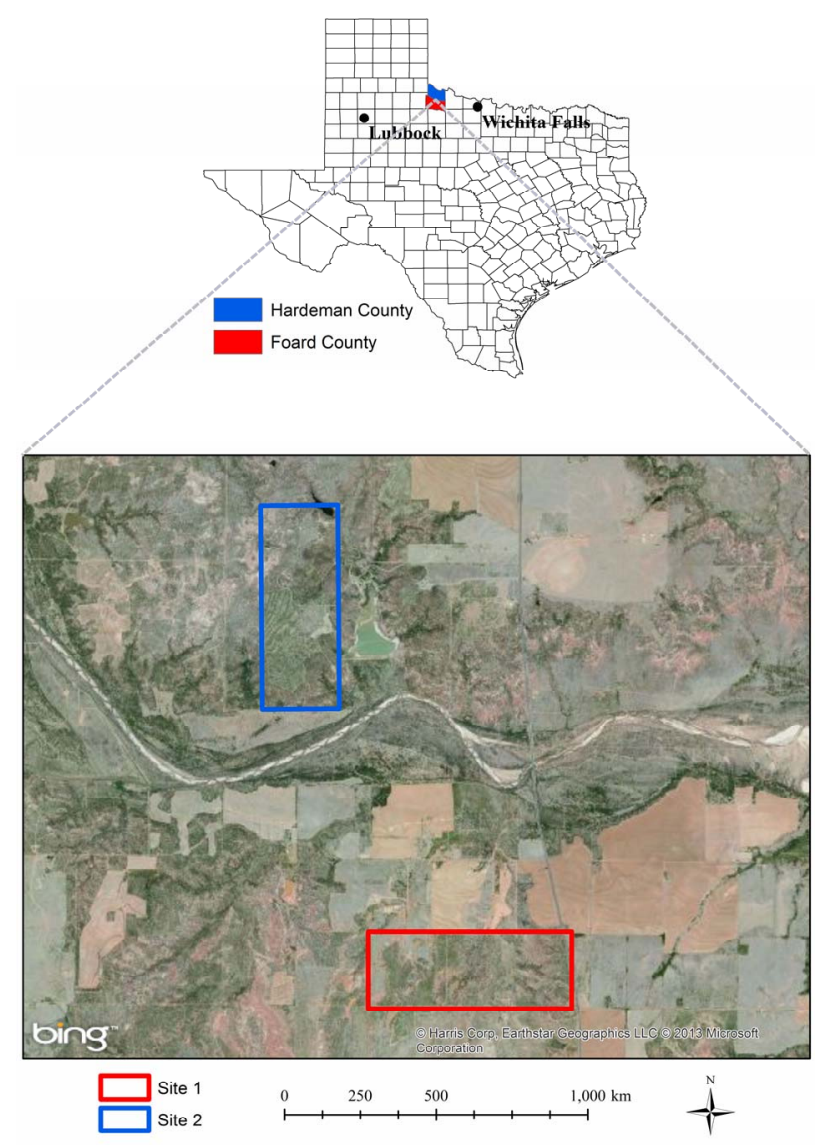

Figure 1. Location of Hardeman (top) and Foard Counties (bottom) where study sites were situated in north central Texas. 
and fine-silty, montmorillonitic, thermic Typic Haplusterts of the Hollister series [31].

\subsection{Field Sampling}

A total of 54 juniper plants ranging in size from 1.53 to $73.90-\mathrm{m}^{2}$ canopy area were selected for the study. The trees were selected to represent the range of three diameter found at the sites, thus were not random because the objective of the study was to quantify the relationship between the tree attributes derived from the imagery and field-measured biomass through regression analysis. To randomly sample the study sites and still have the same range of canopy diameter would have required many more plots than the logistics of the study could accommodate. Selection was limited to trees that appeared healthy and undamaged and had to be at least 1-m apart from other trees. Canopy diameters along 2 directions (longest axis and perpendicular to longest) were measured on each tree followed by harvesting to the ground level during the dormant season (October-December 2010 and January-March 2011). Following harvest, leaftwig $(<3-\mathrm{cm}$ diameter stems) and wood $(>3-\mathrm{cm}$ diameter) components were manually separated and weighed. Total wet weight of each component was obtained within few hours of tree felling. Three randomly selected subsamples of each component from each tree were weighed as wet weight, oven-dried at $60^{\circ} \mathrm{C}$ for 60 - 70 days, and weighed after weights stabilized. Percent moisture was determined [(wet weight-dry weight)/wet weight $\times 100$ ] for components and whole tree and used to determine total oven dry biomass of each tree and individual biomass components.

\subsection{Remote Sensing Imagery and Image Classification}

One county-level color infrared aerial image collected over Hardeman County, covering both sites, was obtained from the National Agricultural Imagery Program (NAIP) provided by the Natural Resources Conservation Service Geospatial Data Gateway at

(http://datagateway.nrcs.usda.gov/). The NAIP imagery consisted of green, red, and near infrared bands with a spatial resolution of 1-m taken on August 12, 2010 over the sites. The image was projected to the Universal Transverse Mercator North American Datum 1983 Zone 14 North by the provider. The image was extracted for the sites using ArcGIS software suits (ESRI, Inc. Redlands, CA).

Image classifications were performed using the SVM method in Environment for Visualizing Images software (ENVI; Exelis Visual Information Solutions, Boulder, $\mathrm{CO})$. The SVM is a supervised machine learning method that performs classification based on the statistical learn- ing theory. The SVM classifies data by separating a hyperplane that provides the best separation between classes in a multidimensional feature space. This hyperplane is the decision surface on which the optimal class separation takes place. The optimal hyperplane is the one that maximizes the distance between the hyperplane and the nearest positive and negative training example called the margin. From a given set of training samples, the optimization problem is solved to find the hyperplane that leads to a sparse solution. Although the SVM is a binary classifier in its simplest form, implementation of the SVM classifier in ENVI was extended to more than two classes by splitting the problem into a series of binary class separations (ENVI User's Guide).

In order to represent more complex shapes than linear hyperplanes, a variety of kernels including the polynomial, the radial basis function, and the sigmoid can be used for performing SVM classification in ENVI. The SVM was employed using the radial basis function kernel for performing the pairwise classification. There is also a penalty parameter can be introduced to the SVM classifier to allow for misclassification during the training process. The penalty parameter was set to its maximum value, whereas a classification probability threshold of zero was used in order to classify all pixels (ENVI User's Guide). Default settings of this classifier were used for image classifications. During the classification process, only NIR band of the NAIP imagery was chosen using the spectral subset option in ENVI.

The 1-m image allowed clear and visual identification of all endmembers based on the spectral contrast among the live vegetation (juniper, mesquite, herbaceous) and senescent or non-vegetative components (road, shadow, exposed soil, water, senescent herbaceous) (Figure 2(a)). Previous studies found that reflectance from Ashe juniper (Juniperus ashei), mesquite, water, exposed soil, and herbaceous plants were significantly different [32,33]. In addition, reflectance variation within deciduous crown is larger than that within coniferous tree crown because of the non-conical shape, large branches, and the shade area caused by the neighboring branches [15]. Thus, juniper endmember was manually extracted from isolated trees on areas in the image [34]. Juniper endmember for each site comprised 10 polygons, each having 25 pixels, from pure juniper canopy at locations well-identified on the ground and on the image. The CEM was run for juniper endmember using covariance matrix with a $75 \%$ rule threshold and square root stretching.

\subsection{Determination of Canopy Area and Development of Regression Model for Biomass Estimation}

Point coordinates of the harvested trees, with sub-meter accuracy at the center of each tree following harvest, 
were taken with a Trimble GeoXH hand-held unit (Trimble Navigation Limited, Sunnyvale, CA) equipped with the ArcPad software (ESRI, Inc. Redlands, CA). The projection of the GPS unit was set to Universal Transverse Mercator North American Datum 1983 Zone 14 North. A unique identification number was assigned to each tree during the collection of point coordinates in the field. Spatial analyses performed for juniper canopy area determination are described below.

Following image classification using CEM, fractional abundance of juniper was converted to vector layer (polygon shapefile format) in ENVI and exported to ArcGIS for canopy area determination (Figure 2(b)). The point coordinates representing tree-locations were overlaid onto the vector layer (Figure 2(c)) and the polygons representing harvested tree were selected with the "select by location" function, where the locations were tree point coordinates. A new polygon layer including only selected polygons was created (Figure 2(d)). This new polygon layer and point layer, both representing harvested trees, were "joined" in order to assigned unique identification number to each polygon. Area of each polygon was determined with "calculate geometry" function and designated as canopy area. The attribute table of the circle layer was then exported to a spreadsheet in order to perform regression analysis with fieldmeasured tree attributes.

The point coordinates representing to tree-locations were overlaid onto the image where one-to-one matching with the juniper trees was verified (Figure 2(c)). Circles representing juniper canopy area based on point locations were blindly digitized as a polygon layer by an untrained person in ArcGIS (Figure 2(c)). The areas and diameters of these circles were determined by the "calculate ge-

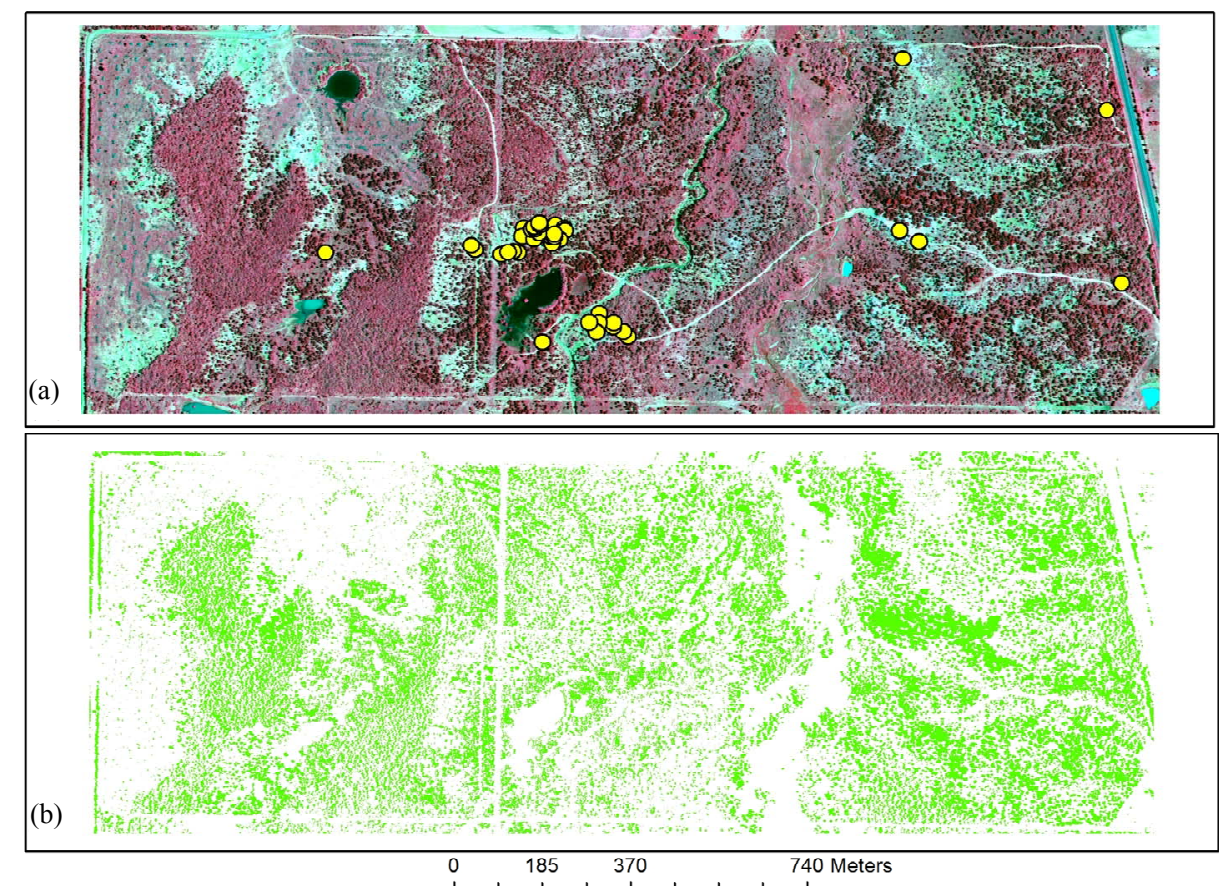

(a)

$185370 \quad 140$ Meters

(c)

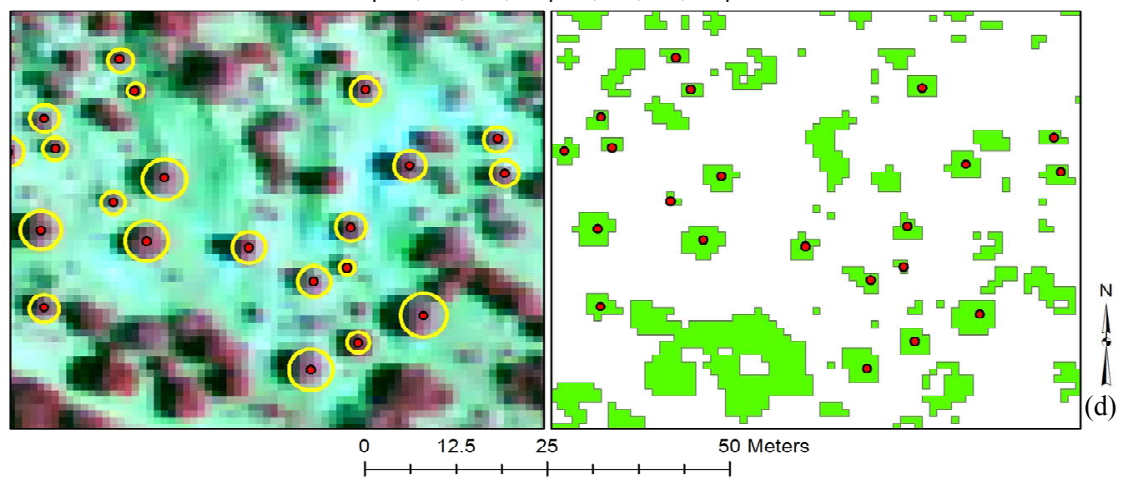

Figure 2. The false color infrared national agricultural imagery program image with 1-m spatial resolution and harvested trees represented with yellow (a); classified image with juniper: green (b); some of the harvest trees illustrated with blindly drown circles in yellow and red dots (c); classified trees shown with the red dots (d) for site 1. 
ometry" and "field calculator" functions, respectively. The attribute table of the circle layer was then exported to a spreadsheet in order to perform regression analysis with field-measured tree attributes. Field-based canopy area $\left(\mathrm{CA} ; \mathrm{m}^{2}\right)$ determination was made using the ellipse equation: $\pi \cdot a \cdot b$, where $a=$ radius of longest canopy axis and $b=$ radius of perpendicular canopy axis adopted from [10].

Simple linear regression analyses were performed to relate image-derived tree attributes with field-measured tree variables using Statistical Analysis Systems 9.2 (SAS Institute Inc., Cary, NC) and regression plots were created using SigmaPlot 11 (Systat Software Inc., Chicago, IL). Image-derived tree parameters were used as the independent and field-measured attributes were set as the dependent variable. Model validation was performed by randomly apportioning observations into a 70/30 split with the former fraction being used for model development, while later used to predict tree attributes. Error estimation was performed by computing the root mean squared error (RMSE) between predicted and field-measured values, as well as field-measured and imageryderived attributes.

\section{Results}

\subsection{Data Summary}

Descriptive summary of variables used in regression models were presented in Table $\mathbf{1}$. The means and ranges confirm that a broad range of values was assessed for tree attributes. Field measured juniper plant canopy diameters ranged from 1.40 to $9.70-\mathrm{m}$ with a mean and standard error $(\overline{\mathrm{x}} \pm \varepsilon: 5.15 \pm 0.31)$, whereas canopy areas varied from 1.72 to $73.90-\mathrm{m}^{2}(24.73 \pm 2.72)$. Average canopy diameters and areas derived from the im-

Table 1. Summary statistics for juniper tree attributes measured in the field and extracted from the imagery with 1-m spatial resolution $(n=54)$.

\begin{tabular}{ccccc}
\hline Tree attribute & Mean & SE & Min & Max \\
\hline Fmca $\left(\mathrm{m}^{2}\right)$ & 24.73 & 2.72 & 1.53 & 73.90 \\
Fmcd $\left(\mathrm{m}^{2}\right)$ & 5.15 & 0.31 & 1.40 & 9.70 \\
Fmtb $[\mathrm{kg}]$ & 187.03 & 25.29 & 3.53 & 688.35 \\
Fmwb $[\mathrm{kg}]$ & 104.78 & 16.41 & 0.05 & 460.37 \\
Fmltb $[\mathrm{kg}]$ & 82.25 & 9.47 & 3.44 & 227.99 \\
Meca $\left(\mathrm{m}^{2}\right)$ & 28.21 & 3.27 & 1.72 & 101.92 \\
Macd $\left(\mathrm{m}^{2}\right)$ & 5.48 & 0.33 & 1.48 & 11.39 \\
Cca $\left(\mathrm{m}^{2}\right)$ & 27.46 & 3.55 & 0.00 & 105.00 \\
\hline
\end{tabular}

Fmca: field-measured canopy area; Fmcd: field-measured canopy diameter; Fmtb: field-measured total biomass; Fmwb: field-measured wood biomass; Fmltb: field-measured leaf-twig biomass; Meca: manually-extracted canopy area; Mecd: manually-extracted canopy diameter; Cca: classified canopy area; SE: Standard Error; Min: Minimum; Max: Maximum. agery using both manual-extraction and classification methods were slightly higher than the field-measurements (Table 1).

Canopy diameter and area for manual extraction method ranged from 1.48 to $11.39 \mathrm{~m}(5.48 \pm 0.33)$ and from 1.72 to $101.92-\mathrm{m}^{2}(22.84 \pm 2.70)$, respectively. Range of canopy areas derived from classified imagery were between 0 and $105-\mathrm{m}^{2}(27.46 \pm 3.55)$, respectively.

A juniper plant with $1.75 \mathrm{~m}$ diameter, and $2.3 \mathrm{~m}^{2}$ canopy area was, however, not detected with the algorithm. Biomass varied from 3.53 to $688.85 \mathrm{~kg}(187.03 \pm 24.83)$. Biomass was partitioned into wood biomass only with a minimum and maximum weights 0.05 and $460.37 \mathrm{~kg}$ $(104.78 \pm 16.41)$ and leaf-twig biomass varying from 3.44 to $227.99 \mathrm{~kg}(82.25 \pm 9.47)$.

\subsection{Biomass Estimation}

Simple linear regression analysis revealed presence of robust, tight, and significant relationships between the variables of interest (Figures 3-6, Table 2). Predictors (classified and manually-extracted canopy area and diameter) accounted for $91 \%$ to $96 \%$ of the variation in fieldmeasured canopy area and diameter with associated RMS errors between 4.274 and 0.489, respectively, (Figure 3). Manually-extracted canopy area produced a slightly stronger relationship with total and wood biomass than canopy diameter (Table 2). Classified canopy area had equal predictive power for total and leaf-twig biomass (Figures 4(a)-(c)), while the predictive power was weaker for wood biomass (Figure 4(b)). The strength of the relationships between biomass components and imagery-derived canopy area or canopy diameter generally declined $\left(r^{2}=0.88\right.$ and RMSE between 5.754 and 5.106) for leaf-twig biomass (Figure 6(d); Table 2), except for the classified canopy area $\left(r^{2}=0.93\right.$; RMSE $=7.751$; Figure 4(c)).

The relationships between remotely determined and field-measured tree attributes using the validation dataset confirmed robust and significant associations (Figures 5 and 6, Table 2). Linear regression between canopy diameter using manual extraction method and field-measured canopy diameter produced a stronger relationship $\left(\mathrm{r}^{2}\right.$ $=0.95$, RMSE $=0.463)($ Figure $5(\mathbf{c}))$ compared to canopy area calculated using both manually-extracted $\left(\mathrm{r}^{2}=\right.$ $0.94, \mathrm{RMSE}=4.287$; Figure 5(a)) and classified data $\left(\mathrm{r}^{2}\right.$ $=0.94$, RMSE $=4.199$; Figure 5(b)), respectively. Total, wood, and leaf-twig biomass determined using classified canopy area accounted for 98\% (RMSE $=16.644)$, 96\% $(\mathrm{RMSE}=15.717)$, and $88 \%(\mathrm{RMSE}=12.495)$ of the variations in field-measured counterparts (Figures 6(a)(c)), respectively. Biomass components estimated using manually-extracted canopy area had $\mathrm{r}^{2}$ values of 0.96 , 0.96 , and 0.84 for field-measured total, wood, and leaftwig biomass (Table 2), respectively, whereas the rela- 

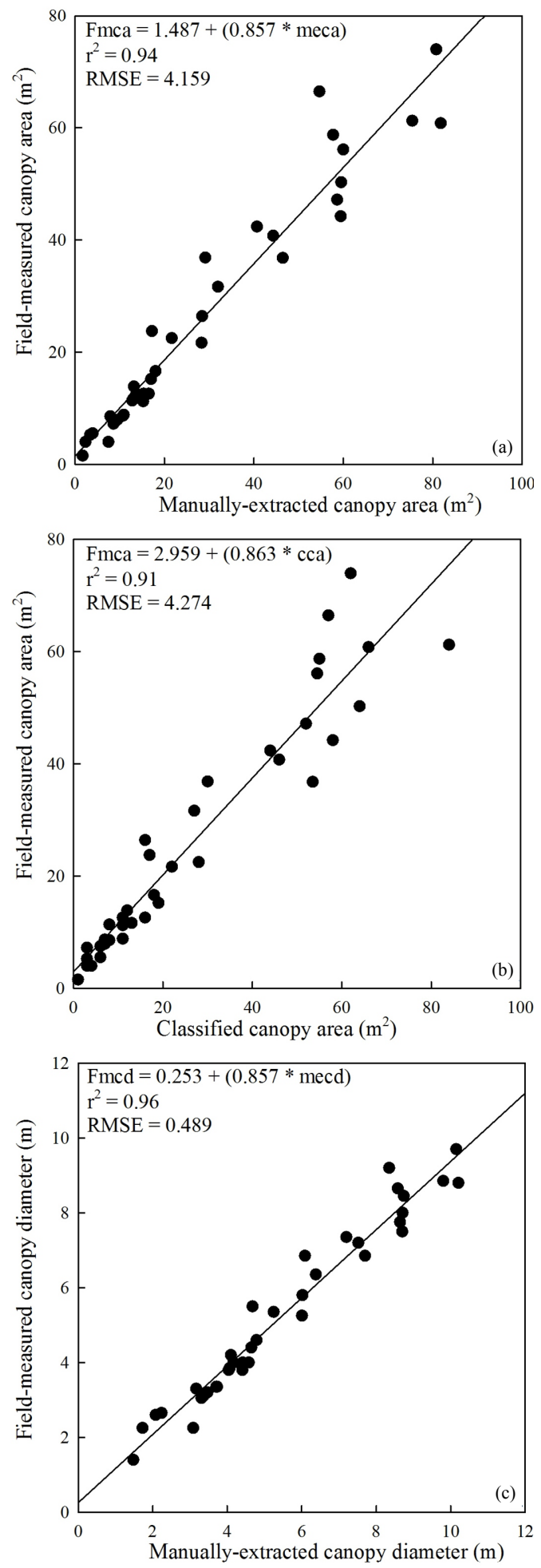

Figure 3. The relationship between manually-extracted and field-measured canopy area (a), classified and field-measured canopy area (b), and manually-extracted and fieldmeasured canopy diameter (c); $\mathbf{n}=38, \mathbf{P}<0.001$. Fmca: field-measured canopy area; meca: manually-extracted canopy area; cca: classified canopy area; fmcd: field-measured canopy diameter; mecd: manually-extracted canopy diameter.
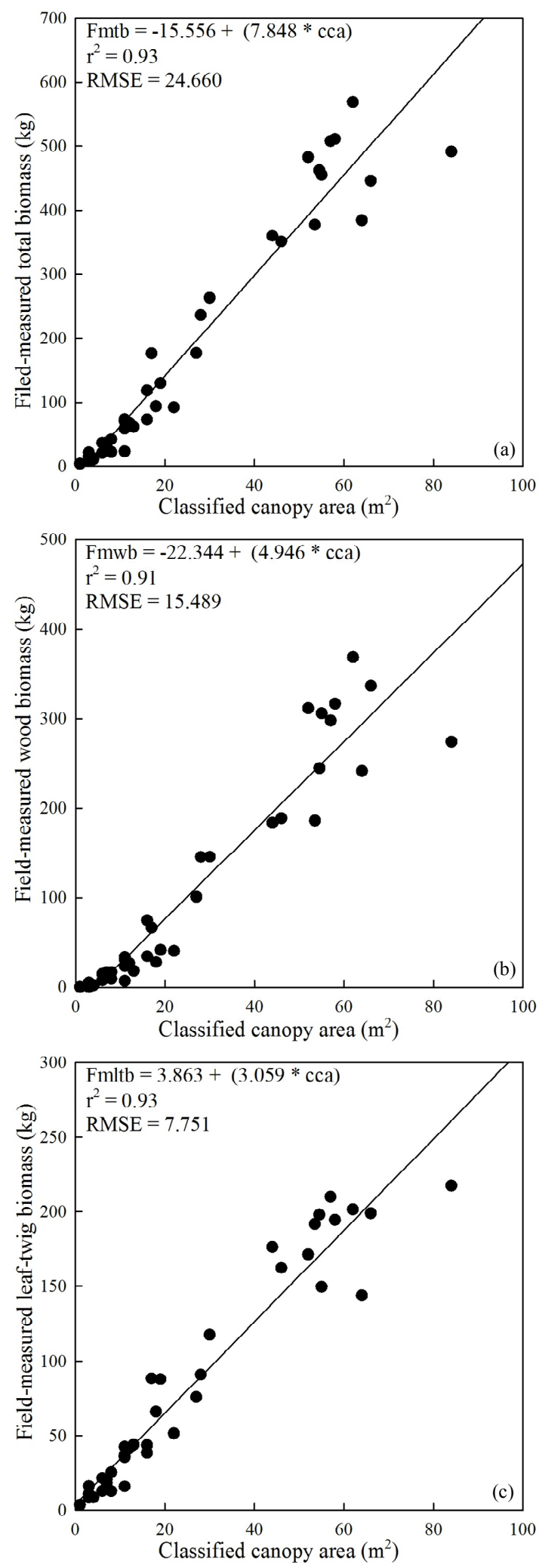

Figure 4. The relationship between classified canopy area and field-measured total (a), wood (b), and leaf-twig biomass (c); $\mathbf{n}=38, \mathbf{P}<0.001$. Fmtb: field-measured total biomass; cca: classified canopy area; fmwb: field-measured wood biomass; fmltb: field-measured leaf-twig biomass. 

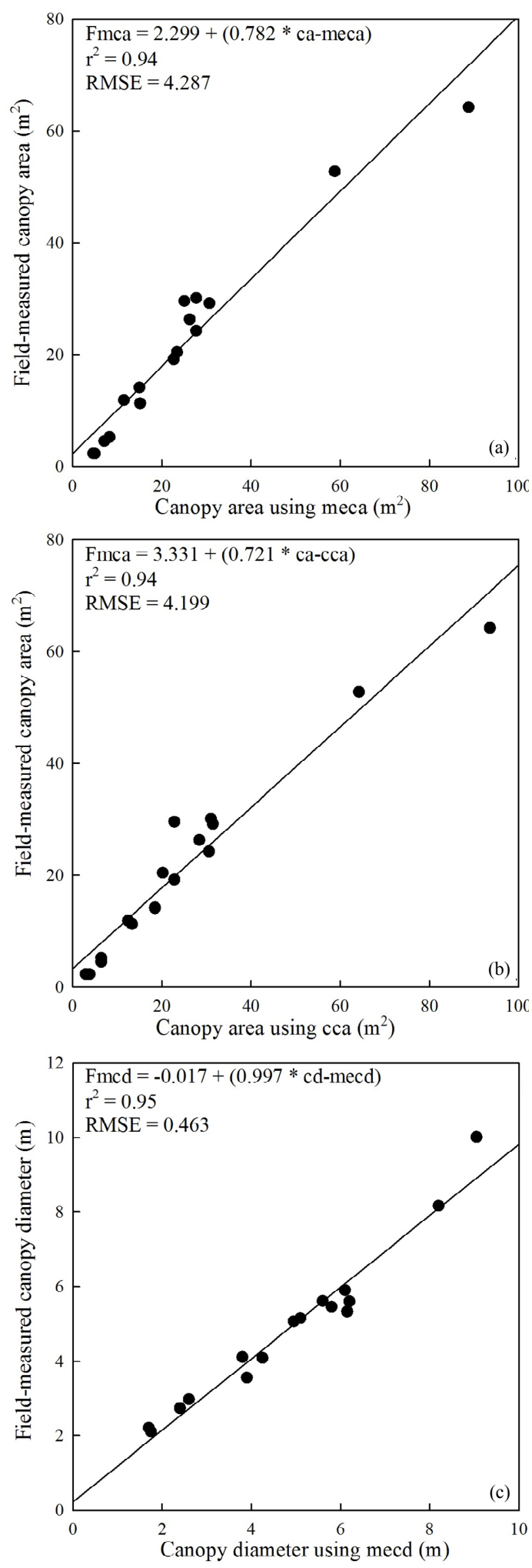

Figure 5. The relationship between canopy area using manually-extracted canopy area (meca) and field-measured canopy area (fmca) (a); canopy area using classified canopy area (cca) and fmca (b); and canopy diameter using manually-extracted canopy diameter (mecd) and field-measured canopy diameter (fmcd) $(\mathrm{c}) ; \mathrm{n}=16, \mathrm{P}<0.001$.
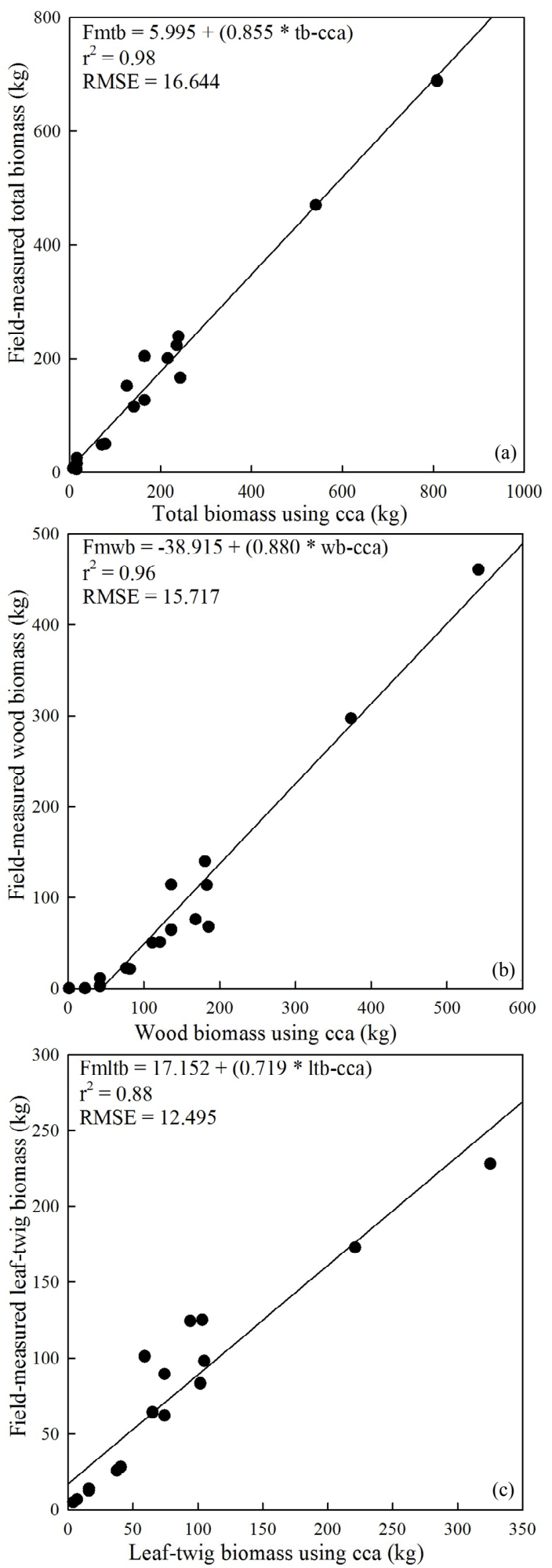

Figure 6. The relationship between total (a), wood (b), and leaf-twig biomass (c) determined from classified canopy area (cca) and field measurements; $n=16, P<0.001$. Fmtb: field-measured total biomass; fmwb: field-measured wood biomass; fmltb: field-measured leaf-twig biomass; tb-, wb-, Itb-cca: total, wood, and leaf-twig biomass using classified canopy area. 
Table 2. The simple linear regression models with the associated statistics for manually-extracted canopy area and diameter versus predicted and field-measured total, wood, and leaf-twig biomass.

\begin{tabular}{lcc}
\hline Biomass model & $\mathrm{r}^{2}$ & RMSE \\
\hline $\mathrm{Fmtb}^{+}=-23.617+\left(7.604^{*}\right.$ meca $)$ & 0.92 & 24.87 \\
$\mathrm{Fmwb}^{+}=-30.581+\left(4.903^{*}\right.$ meca $)$ & 0.93 & 11.58 \\
$\mathrm{Fmltb}^{+}=2.310+\left(2.909^{*}\right.$ meca $)$ & 0.88 & 5.75 \\
$\mathrm{Fmtb}^{+}=-202.34+\left(71.921^{*}\right.$ mecd $)$ & 0.90 & 29.56 \\
$\mathrm{Fmtb}^{+}=-142.143+\left(45.704^{*}\right.$ mecd $)$ & 0.89 & 20.16 \\
$\mathrm{Fmltb}^{+}=-67.776+\left(27.822^{*}\right.$ mecd $)$ & 0.88 & 5.10 \\
$\mathrm{Fmtb}^{*}=8.674+\left(1.457^{*}\right.$ fmtb-meca $)$ & 0.96 & 16.96 \\
$\mathrm{Fmwb}^{*}=-11.972+\left(0.992^{*}\right.$ fmwb-meca $)$ & 0.96 & 5.23 \\
$\mathrm{Fmltb}^{*}=12.208+\left(0.800^{*}\right.$ fmltb-meca $)$ & 0.84 & 5.65 \\
$\mathrm{Fmtb}^{*}=-42.420+\left(1.085^{*}\right.$ fmtb-mecd $)$ & 0.93 & 28.21 \\
$\mathrm{Fmwb}^{*}=-44.061+\left(1.184^{*}\right.$ fmwb-mecd $)$ & 0.90 & 18.48 \\
Fmltb $^{*}=-116.266+\left(0.889^{*}\right.$ fmltb-mecd $)$ & 0.89 & 1.54 \\
\hline
\end{tabular}

${ }^{+}$and ${ }^{*}$ : model development $(\mathrm{n}=38, \mathrm{P}<0.001)$ and validation datasets $(\mathrm{n}=$ $16, \mathrm{P}<0.001$ ), respectively; fmtb: field-measured total biomass; meca: manually-extracted canopy area; fmwb: field-measured wood biomass; fmltb: field-measured leaf-twig biomass; mecd: manually-extracted canopy diameter; ptb-meca, pwb-meca, and pltb-meca: predicted total, wood, and leaf-twig biomass using manually-extracted canopy area, respectively; ptbmecd, pwb-mecd, pltb-mecd: predicted total, wood, and leaf-twig biomass using manually-extracted canopy diameter.

tionships between field-measured total, wood, and leaftwig biomass and biomass of these components determined using manually-extracted canopy diameter were 93\%, 90\%, and $89 \%$ (Table 2), respectively.

\section{Discussion}

We evaluated and reported the usefulness of 2D geospatial aerial imagery for estimating juniper tree biomass at two rangeland sites, typical for the southern Great Plains of the US, using both automated and manual canopy area determination methods. Although accuracy assessment for classification was not conducted in this research, earlier studies found high classification accuracy for juniper species [32,33,35-38]. Overall accuracies between 80 and $92 \%$ were found for classifying Ashe juniper in central Texas using QuickBird imagery and aerial photography [32]. An airborne hyperspectral image was evaluated in order to compare classification methods for mapping Ashe juniper in central Texas [33]. The authors found that overall mapping accuracies varied from $84 \%$ to $100 \%$. Overall classification accuracies between $80 \%$ and $92 \%$ were achieved for both Rocky Mountain juniper (Juniperus scopulorum) and Utah juniper (Juniperus osteosperma) using Landsat 5 TM imagery [38]. A mapping accuracy of $92 \%$ for western juniper (Juniperus occidentalis subsp. Occidentalis) using the NAIP imagery was reported [35].
A single juniper plant with a $2.3-\mathrm{m}^{2}$ canopy area (1.75-m canopy diameter) was not detected with the algorithm used to classify the imagery in this study. Visual inspection of ground-level images of this plant taken prior to harvest indicated that it was growing on $100 \%$ exposed soil without any herbaceous background cover. This suggested that $100 \%$ exposed soil background may suppress detection of smaller plants. Accurate monitoring of semi-arid vegetation using remote sensing can be hindered by the effects of bare soil [39].

Reasons for this may relate to the greater level of "brightness" associated with bare soil in arid and semiarid landscapes that saturates that portion of the image and eliminates detection of small dark objects such as a small tree canopy.

The approach developed and implemented in the current study allows accurate estimation of individual juniper tree biomass using simple linear regression for fieldmeasured biomass and automated or manual methods. The relationships observed between field-measured and image derived juniper plant variables were robust and highly significant. This indicates that remotely sensed imagery can be very useful for estimating biomass of individual juniper trees on rangeland ecosystems for both trained and untrained personnel. For example, automated canopy area determination method over large land areas can be used by trained personnel in image processing software, while manual method can be preferable by untrained rangeland managers. Remote sensing has not been used extensively for quantifying the amount and extent of woody biomass on rangelands. The bulk of the existing studies have relied on other mass quantification techniques, which usually are time-consuming measurements using field transects $[9,28]$. The strength of the relationships found in this study implies that these attributes can be readily obtainable from the image with a sufficient spatial resolution without a need for field measurements, especially over remote and inaccessible or large land areas. The RMSEs reported in this study were far less than that required for biomass estimation procedures in European countries, with an error not exceeding $\pm 20 \%$ [22].

We also explored the use of 2D geospatial imagery not only for total plant biomass estimation but also for estimation of wood and leaf-twig biomass components. Estimates of woody plant components have rarely been related to remotely sensed images [40]. Our results indicated that wood and leaf-twig biomass can be estimated reasonably well with canopy area and diameter values derived from aerial images of the resolution utilized in this study. Wood biomass has the highest energy content of the plant components and would likely be the most desirable portion of woody plants from a bioenergy use perspective. Alternatively, leaf-twig biomass may be 
linked to estimate leaf area index (LAI), providing clues to estimate water use patterns and potential competitive effects with the herbaceous understory. Leaves also conduct photosynthesis and are the primary energy exchange medium between plant and the environment, and are thus linked to productivity and biogeochemical cycles of a site [22,40-43].

The relationships developed between image-measured canopy area and that measured on the site in this study were higher than that reported by [28]. These authors found that the QuickBird data accounted for $85 \%$ of the variation in ground-measured eastern redcedar (Juniperus virginiana) biomass. A stronger relationship $\left(\mathrm{r}^{2}=\right.$ 0.98) than ours between image- and ground-measured eastern redcedar canopy area was reported by [28]. An identical relationship $\left(\mathrm{r}^{2}=0.92\right)$ between LIDAR- and field-measured biomass to ours was reported by [44], whereas a weaker relationship $\left(r^{2}=0.62\right)$ was found by [45] who related LISS-IV-estimated and field-measured biomass. A good relationship $\left(\mathrm{r}^{2}=0.78\right)$ between Aleppo pine (Pinus halepensis) biomass measured in the field and estimated from a high-quality aerial photograph [46]. Image-estimated biomass can serve as an alternative to field sampling in forest biomass research, given adequate temporal and spatial coverage of the study area [46].

Recently, there has been increasing amounts of baseline information required at large spatial scales as part of woody biomass operational management plans. Such details may include ecological diversity issues, partial harvesting (i.e., leaving old and large trees), or patch harvesting for bioenergy, wildlife or hydrological concerns. These new requirements demand a greater level of detail in remote sensing data. Higher resolution data with individual tree-scale details allows for better precision in management decisions [1,3,40,47-49]. The individual plant approach offers a better understanding of the sources of uncertainty and errors associated with remote sensing estimates when predicting biomass at a large scale [48]. With availability of high spatial and spectral resolution, multispectral and hyperspectral satellite and aerial remote sensing data in the recent times, it is now possible to estimate both individual tree and cluster or stand level biomass $[28,40]$ at relatively low resource requirement. The equations derived and validated in this study are easy to comprehend and may be used with high confidence by managers, ecologists, scientists, and ranchers seeking rapid estimates of juniper biomass and possibly other tree species with similar growth forms for use in management and in ecological models.

Accurate estimates of biomass are also critical for monitoring carbon dynamics in rangelands that is considered essential in assessing regional or global carbon budgets. Growing interest in quantifying ecosystem carbon stocks and or potential bioenergy uses has triggered various research initiatives to explore possibilities of using non-destructive methods to estimate biomass [10, 28]. In particular, there has been a noticeable inclination towards using aerial or satellite remote sensing images to estimate biomass [3,28,50-53]. Regional companies are currently considering to use eastern redcedar in gasification facilities for the production of steam or electricity for small rural communities and in ethanol production, or to produce woody pellets for residential heating [28]. With respect to potential biomass estimation for bioenergy uses, the aerial extent of the images will have to be sufficient to cover large land areas ( $>50,000 \mathrm{ha})$ that is necessary for sustainable feedstock supply to a processing facility $[28,54]$. Such estimations may need to rely on 2D imagery such as National Agricultural Imagery Program (NAIP) of the USDA $[35,53,55]$ or satellite images that can provide appreciable details at regional scale and can be geo-spatially integrated with other features such as road networks, waterways, etc. to facilitate harvest plans. Otherwise, if not impossible, it is too costly, labor intensive, and time consuming to estimate biomass via ground-based measurements [28].

Data reported so far worldwide have indicated that for most rangeland woody plants, the most accurate method of non-destructively estimating biomass is to measure basal stem diameter, crown diameter, plant height, and crown volume [7,56-61]. Basal stem diameter and diameter at breast height, however are not easily-measurable parameters for juniper due to its highly compacted canopy and a high density of low growing stems restricting access to the central base stem [10]. Because of spherical growth forms and dense lateral growth with very compact canopy and a high density of low growing stems, these researchers determined that canopy area, determined by measuring canopy diameter in two directions, was the best variable for predicting total tree AGM. Height was a less effective variable to predict biomass and including height to calculate canopy volume resulted in little improvement in the biomass estimation accuracy compared to canopy area alone. Since it is not possible to measure canopy height or stem diameter at breast height from $2 \mathrm{~d}$ geospatial imagery, using canopy area and/or diameter measurements would appear to be the most suitable approach for predicting juniper tree biomass from $2 \mathrm{D}$ imagery. Imagery classification and converting classification to vector to obtain automated canopy area of all trees in an area are the easiest and quickest processes. The ability to remotely estimate biomass using canopy area would provide a major benefit for research and management efforts.

\section{Conclusion}

Though remote sensing data is becoming increasingly important in forest biomass estimation, little attention has 
been directed to rangeland woody biomass. There is an obvious need for large scale measurements to improve our understanding on the effects of ecological processes such as woody encroachment into grasslands and carbon contribution of rangeland woody plants to local or regional carbon stocks. The current study was undertaken to explore the relationship between canopy area and diameter of individual red berry juniper trees as determined via aerial images and the biomass of those trees. A major finding of this research is that the method is highly automated and repeatable, and provides the ability to estimate and map juniper biomass using image classification in addition to manual digitizing. Results suggest that 2D geospatial imagery may be a powerful tool for estimating juniper biomass and in certain situations with adequate ground-based calibration curves, could replace ground measurement in many areas. Imagery classification of woody canopies can be a relatively straightforward process when the imagery is acquired during the dormant season when there is a strong spectral contrast between evergreen juniper and leafless deciduous trees and/or dormant herbaceous plants.

\section{Acknowledgements}

This research was funded in part by a grant from John Deere Renewables, Inc., and the Texas AgriLife Bioenergy Initiative Fund. Copper Breaks State Park and the Whatley Ranch, Crowell, TX provided harvest sites for this project. Images used in this study were made available by the USDA-NRCS. We also thank Mimi Roy for technical discussion and Andy Bell for assisting with data collection.

\section{REFERENCES}

[1] N. F. Glenn, L. P. Spaete, T. T. Sankey, D. R. Derryberry, S. P. Hardegree and J. J. Mitchell, "Errors in LiDAR-Derived Shrub Height and Crown Area on Sloped Terrain," Journal of Arid Environments, Vol. 75, No. 4, 2011, pp. 377-382. doi:10.1016/i.jaridenv.2010.11.005

[2] J. E. Nichol and M. L. R. Sarker, "Improved Biomass Estimation Using the Texture Parameters of Two HighResolution Optical Sensors," IEEE Transactions on Geoscience And Remote Sensing, Vol. 49, No. 3, 2011, pp. 930-948. doi:10.1109/TGRS.2010.2068574

[3] E. K. Strand, L. A. Vierling, A. M. S. Smith and S. C. Bunting, "Net Changes in Aboveground Woody Carbon Stock in Western Juniper Woodlands, 1946-1998," Journal of Geophysical Research D: Atmospheres, Vol. 113, No. G01013, 2008, pp. 1-13.

[4] Z. Wang, C. B. Schaaf, P. Lewis, Y. Knyazikhin, M. A. Schull, A. H. Strahler, T. Yao, R. B. Myneni, M. J. Chopping and B. J. Blair, "Retrieval of Canopy Height Using Moderate-Resolution Imaging Spectroradiometer (MODIS) Data," Remote Sensing of Environment, Vol.
115, No. 6, 2011, pp. 1595-1601. doi:10.1016/j.rse.2011.02.010

[5] K. Brinkmann, U. Dickhoefer, E. Schlecht and A. Buerkert, "Quantification of Aboveground Rangeland Productivity and Anthropogenic Degradation on the Arabian Peninsula Using Landsat Imagery and Field Inventory Data," Remote Sensing of Environment, Vol. 115, No. 2, 2011, pp. 465-474. doi:10.1016/j.rse.2010.09.016

[6] C. Huang, S. E. Marsh, M. P. McClaran and S. R. Archer, "Postfire Stand Structure in a Semiarid Savanna: CrossScale Challenges Estimating Biomass," Ecological Applications, Vol. 17, No. 7, 2007, pp. 1899-1910. doi:10.1890/06-1968.1

[7] E. T. A. Mitchard, S. S. Saatchi, S. L. Lewis, T. R. Feldpausch, I. H. Woodhouse, B. Sonké, C. Rowland and P. Meir, "Measuring Biomass Changes Due to Woody Encroachment and Deforestation/Degradation in a ForestSavanna Boundary Region of Central Africa Using MultiTemporal L-Band Radar Backscatter," Remote Sensing of Environment, Vol. 115, No. 11, 2011, pp. 2861-2873. doi:10.1016/j.rse.2010.02.022

[8] K. P. Paudel and P. Andersen, "Assessing Rangeland Degradation Using Multi Temporal Satellite Images and Grazing Pressure Surface Model in Upper Mustang, Trans Himalaya, Nepal," Remote Sensing of Environment, Vol. 114, No. 8, 2010, pp. 1845-1855. doi:10.1016/i.rse.2010.03.011

[9] R. Sonnenschein, T. Kuemmerle, T. Udelhoven, M. Stellmes and P. Hostert, "Differences in Landsat-Based Trend Analyses in Drylands Due to the Choice of Vegetation Estimate," Remote Sensing of Environment, Vol. 115, No. 6, 2011, pp. 1408-1420. doi:10.1016/j.rse.2011.01.021

[10] R. J. Ansley, M. Mirik, B. W. Surber and S. C. Park, "Canopy Area and Aboveground Mass of Individual Redberry Juniper (Juniperus pinchotii Sudw.) Trees," Rangeland Ecology \& Management, Vol. 65, No. 2, 2012, pp. 189-195. doi:10.2111/REM-D-11-00112.1

[11] M. A. Alrababah, M. N. Alhamad, A. L. Bataineh, M. M. Bataineh and A. F. Suwaileh, "Estimating East Mediterranean Forest Parameters Using Landsat ETM," International Journal of Remote Sensing, Vol. 32, No. 6, 2011, pp. 1561-1574. doi:10.1080/01431160903573235

[12] M. L. Clark, D. A. Roberts, J. J. Ewel and D. B. Clark, "Estimation of Tropical Rain Forest Aboveground Biomass with Small-Footprint Lidar and Hyperspectral Sensors," Remote Sensing of Environment, Vol. 115, No. 11, 2011, pp. 2931-2942. doi:10.1016/j.rse.2010.08.029

[13] S. Englhart, V. Keuck and F. Siegert, “Aboveground Biomass Retrieval in Tropical Forests-The Potential of Combined X- and L-Band SAR Data Use," Remote Sensing of Environment, Vol. 115, No. 5, 2011, pp. 12601271. doi:10.1016/j.rse.2011.01.008

[14] M. T. Gebreslasie, F. B. Admed, J. A. N. Van Aardt and F. Blakeway, "Individual Tree Detection Based on Variable and Fixed Window Size Local Maximum Filtering Applied to IKONOS Imagery for Even-Aged Eucalyptus Plantation Forest," International Journal of Remote Sensing, Vol. 32, No. 15, 2011, pp. 4141-4154. doi: $10.1080 / 01431161003777205$ 
[15] Y. Ke and L. J. Quackenbush, "A Review of Methods for Automatic Individual Tree-Crown Detection and Delineation from Passive Remote Sensing," International Journal of Remote Sensing, Vol. 32, No. 17, 2011, pp. 47254747. doi: $10.1080 / 01431161.2010 .494184$

[16] S. C. Popescu, K. Zhao, A. Neuenschwander and C. Lin, "Satellite Lidar vs. Small Footprint Airborne Lidar: Comparing the Accuracy of Aboveground Biomass Estimates and Forest Structure Metrics at Footprint Level," Remote Sensing of Environment, Vol. 115, No. 11, 2011, pp. 27862797. doi:10.1016/i.rse.2011.01.026

[17] L. R. Sarker and J. E. Nichol, "Improved Forest Biomass Estimates Using ALOS AVNIR-2 Texture Indices," Remote Sensing of Environment, Vol. 115, No. 4, 2011, pp. 968-977. doi:10.1016/j.rse.2010.11.010

[18] C. Yang, H. Huang and S. Wang, "Estimation of Tropical Forest Biomass Using Landsat TM Imagery and Permanent Plot Data in Xishuangbanna, China," International Journal of Remote Sensing, Vol. 32, No. 20, 2011, pp. 5741-5756. doi:10.1080/01431161.2010.507677

[19] E. Næsset, "Estimating Above-Ground Biomass in Young Forests with Airborne Laser Scanning," International Journal of Remote Sensing, Vol. 32, No. 2, 2011, pp. 473-501. doi:10.1080/01431160903474970

[20] G. Sun, K. J. Ranson, Z. Guo, Z. Zhang, P. Montesano and D. Kimes, "Forest Biomass Mapping from Lidar and Radar Synergies," Remote Sensing of Environment, Vol. 115, No. 11, 2011, pp. 2906-2916. doi:10.1016/j.rse.2011.03.021

[21] G. Chen and G. J. Hay, "An Airborne Lidar Sampling Strategy to Model Forest Canopy Height from Quickbird Imagery and GEOBIA," Remote Sensing of Environment, Vol. 115, No. 6, 2011, pp. 1532-1542. doi:10.1016/j.rse.2011.02.012

[22] T. Le Toan, S. Quegan, M. W. J. Davidson, H. Balzter, P. Paillou, K. Papathanassiou, S. Plummer, F. Rocca, S. Saatchi, H. Shugart and L. Ulander, "The BIOMASS Mission: Mapping Global Forest Biomass to Better Understand the Terrestrial Carbon Cycle," Remote Sensing of Environment, Vol. 115, No. 11, 2011, pp. 2850-2860. doi:10.1016/j.rse.2011.03.020

[23] A. Swatantran, R. Dubayah, D. Roberts, M. Hofton and J. B. Blair, "Mapping Biomass and Stress in the Sierra Nevada Using Lidar and Hyperspectral Data Fusion," Remote Sensing of Environment, Vol. 115, No. 11, 2011, pp. 2917-2930. doi:10.1016/j.rse.2010.08.027

[24] C. Song, M. B. Dickinson, L. Su, S. Zhang and D. Yaussey, "Estimating Average Tree Crown Size Using Spatial Information from Ikonos and QuickBird Images: AcrossSensor and Across-Site Comparisons," Remote Sensing of Environment, Vol. 114, No. 5, 2010, pp. 1099-1107. doi:10.1016/j.rse.2009.12.022

[25] P. Gonzalez, G. P. Asner, J. J. Battles, M. A. Lefsky, K. M. Waring and M. Palace, "Forest Carbon Densities and Uncertainties from Lidar, QuickBird, and Field Measurements in California," Remote Sensing of Environment, Vol. 114, No. 7, 2010, pp. 1561-1575. doi:10.1016/j.rse.2010.02.011

[26] R. J. Ansley, H. T. Weidemann, M. J. Castellano and J. E.
Slosser, "Herbaceous Restoration of Juniper-Dominated Grasslands with Chaining and Fire," Rangeland Ecology \& Management, Vol. 59, No. 2, 2006, pp. 171-178. doi:10.2111/05-095R1.1

[27] I. Ozdemir, "Estimating Stem Volume by Tree Crown Area and Tree Shadow Area Extracted from Pan-Sharpened QuickBird Imagery in Open Crimean Juniper Forests," International Journal of Remote Sensing, Vol. 29, No. 19,2008 , pp. 5643-5655.

doi: $10.1080 / 01431160802082155$

[28] P. J. Starks, B. C. Venuto, J. A. Eckroat and T. Lucas, "Measuring Eastern Redcedar (Juniperus virginiana L.) Mass with the Use of Satellite Imagery," Rangeland Ecology \& Management, Vol. 64, No. 2, 2011, pp. 178-186. doi:10.2111/REM-D-10-00057.1

[29] National Oceanic and Atmospheric Administration, Climate Data Center, Asheville, 2006.

http://www.ncdc.noaa.gov/ oa/ncdc.html

[30] NRCS, United States Department of Agriculture, Natural Resource Conservation Service, Plants Database Website, 2011. http://plants.usda.gov

[31] NRCS, United States Department of Agriculture, Natural Resource Conservation Service, Soil Series Descriptions Website, 2011. http://soils.usda.gov

[32] J. H. Everitt, C. Yang and H. B. Johnson, "Canopy Spectra and Remote Sensing of Ashe Juniper and Associated Vegetation," Environmental Monitoring and Assessment, Vol. 130, No. 1-3, 2007, pp. 403-413.

doi:10.1007/s10661-006-9407-2

[33] C. Yang, J. H. Everitt and H. B. Johnson, “Applying Image Transformation and Classification Techniques to Airborne Hyperspectral Imagery for Mapping Ashe Juniper Infestations," International Journal of Remote Sensing, Vol. 30, No. 11, 2009, pp. 2741-2758. doi: $10.1080 / 01431160802555812$

[34] B. Somers, G. P. Asner, L. Tits and P. Coppin, "Endmember Variability in Spectral Mixture Analysis: A Review," Remote Sensing of Environment, Vol. 115, No. 7, 2011, pp. 1603-1616. doi:10.1016/j.rse.2011.03.003

[35] K. W. Davies, S. L. Petersen, D. D. Johnson, D. B. Davis, M. D. Madsen, D. L. Zvirzdin and J. D. Bates, "Estimating Juniper Cover from National Agriculture Imagery Program (NAIP) Imagery and Evaluating Relationships between Potential Cover and Environmental Variables," Rangeland Ecology \& Management, Vol. 63, No. 6, 2010, pp. 630-637. doi:10.2111/REM-D-09-00129.1

[36] S. L. Petersen and T. K. Stringham, "Development of GIS-Based Models to Predict Plant Community Structure in Relation to Western Juniper Establishment," Forest Ecology and Management, Vol. 256, No. 5, 2008, pp. 981-989. doi:10.1016/j.foreco.2008.05.058

[37] T. T. Sankey, N. Glenn, S. Ehinger, A. Boehm and S. Hardegree, "Characterizing Western Juniper Expansion via a Fusion of Landsat 5 Thematic Mapper and Lidar data," Rangeland Ecology \& Management, Vol. 63, No. 5, 2010, pp. 514-523. doi:10.2111/REM-D-09-00181.1

[38] T. T. Sankey and M. J. Germino, "Assessment of Juniper Encroachment with the Use of Satellite Imagery and Geospatial Data," Rangeland Ecology \& Management, Vol. 
61, No. 4, 2008, pp. 412-418. doi:10.2111/07-141.1

[39] K. Hufkens, J. Bogaert, Q. H. Dong, L. Lu, C. L. Huang, M. G. Ma, T. Che, X. Li, F. Veroustraete and R. Ceulemans, "Impacts and Uncertainties of Upscaling of Remote-Sensing Data Validation for a Semi-Arid Woodland," Journal of Arid Environments, Vol. 72, No. 8, 2008, pp. 1490-1505. doi:10.1016/j.jaridenv.2008.02.012

[40] R. M. Lucas, A. C. Lee and P. J. Bunting, "Retrieving Forest Biomass through Integration of CASI and LIDAR Data," International Journal of Remote Sensing, Vol. 29, No. 5, 2008, pp. 1553-1577. doi:10.1080/01431160701736497

[41] D. F. Levia Jr., "A Generalized Allometric Equation to Predict Foliar Dry Weight on the Basis of Trunk Diameter for Eastern White Pine (Pinus strobus L.)," Forest Ecology and Management, Vol. 255, No. 5-6, 2008, pp. 1789-1792. doi:10.1016/j.foreco.2007.12.001

[42] S. D. Roberts, T. J. Dean, D. L. Evans, J. W. McCombs, R. L. Harrington and P. A. Glass, "Estimating Individual Tree Leaf Area in Loblolly Pine Plantations Using LiDAR-Derived Measurements of Height and Crown Dimensions," Forest Ecology and Management, Vol. 213, No. 1-3, 2005, pp. 54-70. doi:10.1016/j.foreco.2005.03.025

[43] L. Wang, J. E. R. Hunt, J. J. Qu, X. Hao and C. S. T. Daughtry, "Towards Estimation of Canopy Foliar Biomass with Spectral Reflectance Measurements," Remote Sensing of Environment, Vol. 115, No. 3, 2011, pp. 836840. doi:10.1016/j.rse.2010.11.011

[44] R. M. Lucas, N. Cronin, M. Moghaddam, A. Lee, J. Armston, P. Bunting and C. Witte, "Integration of Radar and Landsat-Derived Foliage Projected Cover for Woody Regrowth Mapping, Queensland, Australia," Remote Sensing of Environment, Vol. 100, No. 3, 2006, pp. 388-406. doi:10.1016/j.rse.2005.09.020

[45] R. Madugundu, V. Nizalapur and C. C. Jha, "Estimation of LAI and Above-Ground Biomass in Deciduous Forests: Western Ghats of Karnataka, India," International Journal of Applied Earth Observation and Geoinformation, Vol. 10, No. 2, 2008, pp. 211-219. doi:10.1016/j.jag.2007.11.004

[46] A. B. Massada, Y. Carmel, G. E. Tzur, J. M. Grünzweig and D. Yakir, "Assessment of Temporal Changes in Aboveground Forest Tree Biomass Using Aerial Photographs and Allometric Equations," Canadian Journal of Forestry Research, Vol. 36, No. 10, 2006, pp. 2585-2594. doi:10.1139/x06-152

[47] H. Holmström, "Estimation of Single-Tree Characteristics Using the $k N N$ Method and Plotwise Aerial Photograph Interpretations," Forest Ecology and Management, Vol. 167, No. 1-3, 2002, pp. 303-314. doi:10.1016/S0378-1127(01)00720-4

[48] S. C. Popescu, "Estimating Biomass of Individual Pine Trees Using Airborne Lidar," Biomass and Bioenergy, Vol. 31, No. 9, 2007, pp. 646-655. doi:10.1016/j.biombioe.2007.06.022

[49] G. Whiteman and J. R. Brown, "Assessment of a Method for Mapping Woody Plant Density in a Grassland Metrix," Journal of Arid Environments, Vol. 38, No. 2, 1998, pp. 269-282. doi:10.1006/jare.1997.0325
[50] G. P. Asner, S. Archer, R. F. Hughes, R. J. Ansley and C. A. Wessman, "Net Changes in Regional Woody Vegetation Cover and Carbon Storage in Texas Drylands, 19371999," Global Change Biology, Vol. 9, No. 3, 2003, pp 316-335. doi:10.1046/j.1365-2486.2003.00594.x

[51] C. Huang, G. P. Asner, R. E. Martin, N. N. Barger and J. C. Neff, "Multiscale Analysis of Tree Cover and Aboveground Carbon Stocks in Pinyon-Juniper Woodlands," Ecological Applications, Vol. 19, No. 3, 2009, pp. 668681. doi:10.1890/07-2103.1

[52] O. Masera, A. Ghilardi, R. Drigo and M. Angel Trossero, "WISDOM: A GIS-Based Supply Demand Mapping Tool for Woodfuel Management," Biomass and Bioenergy, Vol. 30, No. 7, 2006, pp. 618-637. doi:10.1016/j.biombioe.2006.01.006

[53] M. Mirik and R. J. Ansley, "Comparison of Groundmeasured and Image-Classified Honey Mesquite (Prosopis glandulosa) Canopy Cover in Texas," Rangeland Ecology \& Management, Vol. 65, No. 1, 2012, pp. 85-95. doi:10.2111/REM-D-11-00073.1

[54] R. J. Ansley, M. Mirik and M. J. Castellano, "Structural Biomass Partitioning in Regrowth and Undisturbed Mesquite (Prosopis glandulosa): Implications for Bioenergy Uses," Global Change Biology Bioenergy, Vol. 2, No. 1, 2010, pp. 26-36. doi:10.1111/j.1757-1707.2010.01036.x

[55] E. Strand, A. Smith, S. Bunting, L. Vierling, D. Hann and P. Gessler, "Wavelet Estimation of Plant Spatial Patterns in Multitemporal Aerial Photography," International Journal of Remote Sensing, Vol. 27, No. 10, 2006, pp. 20492054. doi:10.1080/01431160500444764

[56] E. N. Chidumayo, "Above-Ground Woody Biomass Structure and Productivity in a Zambezian Woodland," Forest Ecology and Management, Vol. 36, No. 1, 1990, pp. 33-46. doi:10.1016/0378-1127(90)90062-G

[57] A. Lufafa, I. Diédhiou, N. A. S. Ndiaye, M. Séné, F. Kizito, R. P. Dick and J. S. Noller, "Allometric Relationships and Peak-Season Community Biomass Stocks of Native Shrubs in Senegal's Peanut Basin," Journal of Arid Environments, Vol. 73, No. 3, 2009, pp. 260-266. doi:10.1016/j.jaridenv.2008.09.020

[58] B. K. Northup, S. F. Zitzer, S. Archer, C. R. McMurtry and T. W. Boutton, "Above-Ground Biomass and Carbon and Nitrogen Content of Woody Species in a Subtropical Thornscrub Parkland," Journal of Arid Environments, Vol. 62, No. 1, 2005, pp. 23-43. doi:10.1016/i.jaridenv.2004.09.019

[59] L. F. Ohmann, D. F. Grigal and R. B. Brander, "Biomass Estimation for Five Shrubs from Northeastern Minnesota," Research Paper NC-133, US Department of Agriculture, Forest Service, North Central Forest Experiment Station, St. Paul, 1976.

[60] A. Rosenschein, T. Tietema and D. O. Hall, "Biomass Measurement and Monitoring of Trees and Shrubs in a Semi-Arid Region of Central Kenya," Journal of Arid Environments, Vol. 42, No. 2, 1999, pp. 97-116. doi:10.1006/jare.1999.0509

[61] T. Tietema, "Biomass Determination of Fuelwood Trees and Bushes of Botswana, Southern Africa," Forest Ecology and Management, Vol. 60, No. 3-4, 1993, pp. 257269. doi:10.1016/0378-1127(93)90083-Y 